\title{
Study on novel antibacterial and antiviral compounds from abalone as an important marine mollusc
}

\begin{abstract}
Infectious diseases caused by bacteria and viruses are the most common cause of death in developing countries. The acquisition of antibiotic resistance and emergence of new pathogens require the development of new antibacterial and antiviral compounds with different mechanism of action. Abalone, a commercially important marine mollusc, has recently been found to possess arrange of compounds with potent antibacterial and antiviral activity. Some of the active compounds identified in abalones, such as antimicrobial peptides (AMP) and hemocyanin, demonstrated diverse mechanisms of action against a wide variety of human pathogens. These promising lead compounds may provide a development platform for novel antibacterial and antiviral drugs in the near future.
\end{abstract}

Keywords: antibacterial, antiviral, abalone, antimicrobial peptides (AMP), hemocyanin, herpes simplex virus

\author{
Volume 7 Issue 3 - 2018 \\ Jiada Wu, I Moh Fareed Sairi,2 Tony \\ Cunningham,3 Vincent Gomes, I Fariba \\ Dehghani, I PeterValtchev I \\ 'School of Chemical and Biomolecular Engineering, The \\ University of Sydney, Australia \\ ${ }^{2} \mathrm{~S} c h o o l$ of Biosciences and Biotechnology, University Kebangsan, \\ Malaysia \\ ${ }^{3}$ Westmead Institute of Medical Research, The University of \\ Sydney, Australia
}

\begin{abstract}
Correspondence: Peter Valtchev, School of Chemical and Biomolecular Engineering, The University of Sydney, Sydney, Australia, Tel +6/2 935/4794,
\end{abstract}

Email peter.valtchev@sydney.edu.au

Received: May 19,2018 | Published: May 30, 2018

\section{Introduction}

Despite the remarkable breakthroughs and successes achieved by modern medicine, the ancestral threat of infectious diseases caused by bacteria and viruses remains a serious threat. It is estimated that the current annual death rate attributed to severe infection, 13 to 15 million, will remain until $2030 .{ }^{1}$ Under the pressure of drugresistance and emergence of new pathogens, discovering novel leading compounds from natural products with antibacterial and antiviral properties are highly desirable. ${ }^{2}$ Marine molluscs seem to be a promising source for discovery of new drugs for infectious diseases. As the second-most-diverse phylum, ${ }^{3,4}$ marine molluscs successfully live in an environment containing 1 million bacteria and 10 million viruses per millilitre, ${ }^{3,5}$ which demonstrate robust immunities to combat the infectious pathogens of the ocean..$^{6,7}$

Among various marine molluscs, investigating the antibacterial and antiviral activities of abalone has recently attracted attention. As the commercially important species for aquaculture with the projected value of up to $\$ 3.1$ billion in 2022 in Australia, ${ }^{8,9}$ their innate immunity against abalone infectious pathogens is a crucial factor that significantly impacts the aquaculture market. Apart from being a delicious seafood, abalones are believed by many cultures to bring pronounced health benefits. ${ }^{10}$ This belief has recently been verified by some of the latest studies with abalones, which revealed the profound potential of this marine mollusc for the discovery of novel antibacterial and antiviral drugs. ${ }^{11-13}$

\section{Compounds with antibacterial activity isolated from abalone}

As a marine mollusc without adaptive immunity, abalone is believed to depend exclusively on the innate immunity, to combat bacterial infection. ${ }^{14}$ The innate immunity of invertebrates is facilitated by cellular and humoral systems. ${ }^{14}$ The cellular immunity predominantly involves the phagocytic activity of hemocyte cells while humoral immunity requires the release of antimicrobial factors that kill pathogenic bacteria. The latter involves hemocyanin, the respiratory protein of the mollusc,${ }^{15}$ which has been found to possess the promising antibacterial activity in the host immunity when infection occurs. ${ }^{16,17}$

The antibacterial activity of hemocyanin has been widely identified in numerous studies on invertebrates, including molluscs ${ }^{18-21}$ and arthropods. ${ }^{22-26}$ Hemocyanin is structurally related to Phenoloxidase $\mathrm{e}^{27,28}$ and acquires stronger antibacterial activity when treated with sodium dodecyl sulphate ${ }^{28}$ or after activation by microbial proteases..$^{29}$ Phenoloxidase is important in invertebrates as the initial step in melanin production cascade, which also produces reactive oxygen species (ROS). ROS-mediated antimicrobial activity is a powerful strategy to counter bacterial infection in invertebrates..$^{28}$ On the other hand, several studies demonstrated the role of abalone hemocyanin as a precursor for antimicrobial peptides (AMP). ${ }^{19,30}$

The AMPs identified from abalone hemocyanin, such as Abhisin, Defensins, and Haliotisin, demonstrated a broad-spectrum of antibacterial properties against both Gram-positive and Gramnegative bacteria. ${ }^{30-32}$ The proposed mechanism of antibacterial activity of these AMPs includes but is not limited to: damaging the bacterial cell wall, binding to the DNA and RNA, and direct inhibition of bacterial cell growth. ${ }^{30-32}$ The strong bacteriostatic activity observed with these AMPs suggest that one AMP could possess more than one antibacterial mechanism. ${ }^{30-32}$ These findings explain the identified broad-spectrum antibacterial ability of AMPs derived from abalone hemocyanin, which may prove useful in combating antibiotic resistant bacteria. 


\section{Compounds with antiviral activity isolated from abalones}

The antiviral activity of abalone sera has been observed and confirmed mainly for Haliotis laevigate, $\mathrm{H}$ rubra and their hybrid species. ${ }^{11-13,33,34}$ This was first observed during the outbreak of abalone herpesvirus causing abalone ganglioneuritis in Australia. ${ }^{35}$ Even though about $95 \%$ of abalones died within 14 days after the appearance of clinical signs, the occurrence of naturally surviving abalone implies that these marine gastropods possibly possess the ability to resist viral infection. ${ }^{11}$ Due to the lack of a cell culture model for propagating abalone herpesvirus34, Herpes Simplex Virus type 1 (HSV-1), the well-characterised human herpesvirus that shares $80 \%$ genomic similarity with the abalone herpesvirus, was initially used to investigate the innate antiviral activity of abalone. ${ }^{11}$ Interestingly, at least two fractions with potent antiviral activity against HSV-1 were confirmed in vitro. ${ }^{11,34}$ One was the lipophilic extract of the abalone digestive gland, which acts at the intracellular stage of infection, and another one was the hemocyanin present in the abalone hemolymph that prevents infection by blocking viral entry. ${ }^{12,13,34}$

Compared with the lipophilic extract, the unique mechanism of action demonstrated by hemocyanin attracted more attention, since it could be a promising candidate for the discovery of a novel antiherpetic drugs. Current antivirals against HSV such as the DNA polymerase inhibitor acyclovir, which was modelled upon anti-viral nucleosides isolated from sea sponges, do not decrease the frequency or recurrence and are not effective in immunocompromised patients. Therefore, compounds with alternative mechanism of activity are needed and could potentially increase the effectiveness of current antivirals in concomitant application.

Systematic studies about abalone hemocyanin have been conducted to elucidate its antiviral activity thoroughly. It has been confirmed that the abalone hemocyanin possesses the ability to block HSV-1 entering host cells by selectively binding to essential viral glycoproteins responsible for viral attachment and entry. ${ }^{12,13}$ After dissociating the higher order structure of abalone hemocyanin, the antiherpetic activity was found to be retained. ${ }^{12}$ These findings indicated the feasibility of discovering novel antiviral drugs based on the interaction of abalone hemocyanin with viral glycoproteins. Following these promising findings, more studies on abalone hemocyanin have been conducted to elucidate its structure, ${ }^{36}$ thermal stability ${ }^{37}$ and optimised formulation to maintain its antiviral activity. ${ }^{12}$

\section{Conclusion}

Natural products continue to be a major source of pharmaceuticals due to the fact that their diversity surpasses any combinatorial library available today Identified antibacterial and antiviral compounds from abalone are prime example that highlights the potential of this commercially important marine mollusc to fulfil medicinal proposes. Even though more comprehensive investigations are required to move these leading compounds from bench to bedside, it is evident that compounds isolated from abalones could be used as platform for the discovery of novel antibacterial and antiviral drugs.

\section{Acknowledgements}

None.

\section{Conflict of interest}

The author declares that there is no conflict of interest.

\section{References}

1. Heesterbeek H, Anderson RM, Andreasen V, et al. Modeling infectious disease dynamics in the complex landscape of global health. Science. $2015 ; 347$.

2. Jones KE, Patel NG, Levy MA, et al. Global trends in emerging infectious diseases. Nature. 2008;451:990-93.

3. Dang VT, Benkendorff K, Green T, et al. Marine Snails and Slugs: a Great Place To Look for Antiviral Drugs. Journal of virology. 2015;89:81148118 .

4. Lydeard C, Cowie RH, Ponder WF, et al. The global decline of nonmarine mollusks. Bio Science. 2004;54(4):321-330.

5. Suttle CA. Marine viruses-major players in the global ecosystem. Nat Rev Microbiol. 2007;5:801-12.

6. Liu H, Söderhäll K, Jiravanichpaisal P. Antiviral immunity in crustaceans. Fish \& shellfish immunology. 2009;27(2):79-88.

7. Hooper C, Day R, Slocombe R, et al. Stress and immune responses in abalone: limitations in current knowledge and investigative methods based on other models. Fish \& Shellfish Immunology. 2007;22(4):363-379.

8. Anthony M, Rajesh J. Aquaculture of two commercially important molluscs (abalone and lipet): existing knowledge and future prospects. Reviews in Aquaculture. 2017.

9. Mobsby D, Bath A, Curtotti R. Outlook to 2022-23 Agricultural Commodities. 2018;8:128-137.

10. Suleria HAR, Hines BM, Addepalli R, et al. In vitro Anti-Thrombotic Activity of Extracts from Blacklip Abalone (Haliotis rubra) Processing Waste. Mar Drugs. 2017;15(1).

11. Talaei Zanjani N, Miranda-Saksena M, Valtchev $\mathrm{P}$, et al. Abalone hemocyanin blocks the entry of herpes simplex virus 1 into cells: a potential new antiviral strategy. Antimicrob Agents Chemother. 2016;60(2):1003-12.

12. Zanjani NT, Sairi F, Marshall G, et al. Formulation of abalone hemocyanin with high antiviral activity and stability. European Journal of Pharmaceutical Sciences. 2014;53:77-85.

13. Dang VT, Speck P, Doroudi M, et al. Variation in the antiviral and antibacterial activity of abalone Haliotis laevigata, H. rubra and their hybrid in South Australia. Aquaculture. 2011;315:242-249.

14. Suleria H, Hines B, Addepalli R, et al. In vitro Anti-Thrombotic Activity of Extracts from Blacklip Abalone (Haliotis rubra) Processing Waste. Mar Drugs. 2017;15(1):8.

15. Ellis R, Parry H, Spicer J, et al. Immunological function in marine invertebrates: responses to environmental perturbation. Fish shellfish immunology. 2011;30(6):1209-1222.

16. Mark1 J. Evolution of molluscan hemocyanin structures. Biochimica et Biophysica Acta. 2013;1834(9):1840-1852.

17. Coates CJ, Decker H. Immunological properties of oxygen-transport proteins: hemoglobin, hemocyanin and hemerythrin. Cell Mol Life Sci. 2017;74(2):293-317.

18. Coates CJ, Nairn J. Diverse immune functions of hemocyanins. Developmental and Comparative Immunology. 2014;45(1):43-55. 
19. Li C, Zhu J, Wang Y, et al. Antibacterial Activity of AI-Hemocidin 2, a Novel N-Terminal Peptide of Hemoglobin Purified from Arca inflata. Marine drugs. 2017;15(7):205.

20. Seo J-K, Go H-J, Kim C-H, et al. Antimicrobial peptide, hd Molluscidin, purified from the gill of the abalone, Haliotis discus. Fish shellfish immunology. 2016;52:289-297.

21. Dolashka P, Dolashki A, Beeumen JV, et al. Antimicrobial activity of molluscan hemocyanins from Helix and Rapana snails. Curr Pharm Biotechnol. 2016;17(3):263-270.

22. Seo J-K, Lee MJ, Nam B-H, et al. cg Molluscidin, a novel dibasic residue repeat rich antimicrobial peptide, purified from the gill of the Pacific oyster, Crassostrea gigas. Fish shellfish immunology. 2013;35:480-488.

23. Qin Z, Babu VS, Wan Q, et al. Antibacterial activity of hemocyanin from red swamp crayfish (Procambarus clarkii). Fish shellfish immunology. 2018;75:391-399.

24. Petit VW, Rolland JL, Blond A, et al. A hemocyanin-derived antimicrobial peptide from the penaeid shrimp adopts an alpha-helical structure that specifically permeabilizes fungal membranes. Biochimica Biophysica Acta. 2016;1860(3):557-568.

25. Yan F, Zhang YL, Jiang RP, et al. Identification and agglutination properties of hemocyanin from the mud crab (Scylla serrata). Fish Shellfish Immunol. 2011;30(1):354-360.

26. Zhang Y, Yan F, Hu Z, et al. Hemocyanin from shrimp Litopenaeus vannamei shows hemolytic activity. Fish Shellfish Immunol. 2009;27(2):330-335.

27. Lee SY, Lee BL, Söderhäll K. Processing of an antibacterial peptide from hemocyanin of the fresh water crayfish Pacifastacus leniusculus. Journal of Biological Chemistry. 2003;278(10):7927-33.

28. Manubens A, Salazar F, Haussmann D, et al. Concholepas hemocyanin biosynthesis takes place in the hepatopancreas, with hemocytes being involved in its metabolism. Cell and tissue research. 2010;342:423-35.

29. Coates CJ and Nairn J. Hemocyanin-derived phenoloxidase activity: A contributing factor to hyperpigmentation in Nephrops norvegicus. Food Chem. 2013;140(1-2):361-9.
30. Jiang N, Tan NS, Ho B, et al. Respiratory protein-generated reactive oxygen species as an antimicrobial strategy. Nature immunology. 2007;8(10):1114-22.

31. Zhuang J, Coates CJ, Zhu H, et al. Identification of candidate antimicrobial peptides derived from abalone hemocyanin. Dev Comp Immunol. 2015;49(1):96-102.

32. De Zoysa M, Nikapitiya C, Whang I, et al. Abhisin: a potential antimicrobial peptide derived from histone H2A of disk abalone (Haliotis discus discus). Fish shellfish immunology. 2009;27(5):639-46.

33. De Zoysa M, Whang I, Lee Y, et al. Defensin from disk abalone Haliotis discus: molecular cloning, sequence characterization and immune response against bacterial infection. Fish Shellfish Immunol. 2010;28(2):261-6.

34. Dang VT, Benkendorff $\mathrm{K}$, Corbeil S, et al. Immunological changes in response to herpesvirus infection in abalone Haliotis laevigata and Haliotis rubra hybrids. Fish Shellfish Immunol. 2013;34(2):688-691.

35. Dang VT, Benkendorff K, Speck P. In vitro antiviral activity against herpes simplex virus in the abalone Haliotis laevigata. Journal of General Virology. 2011;92:627-637.

36. Hooper C, Day R, Slocombe R, et al. Stress and immune responses in abalone: limitations in current knowledge and investigative methods based on other models. Fish Shellfish Immunol. 2007;22(4):363-79.

37. Akhtar J, Shukla D. Viral entry mechanisms: cellular and viral mediators of herpes simplex virus entry. Febs Journal. 2009;276(4):7228-7236.

38. Wu J, Cunningham AL, Dehghani F, et al. Comparison of Haliotis rubra hemocyanin isoforms 1 and 2. Gene Reports. 2016;4:123-130.

39. Marshall G, Valtchev P, Dehghani F, et al. Thermal denaturation and protein stability analysis of Haliotis rubra hemocyanin. Journal of Thermal Analysis and Calorimetry. 2016;123(3):2499-2505. 